Int. J. Dev. Biol. 57: 793-797 (2013)

doi: $10.1387 / \mathrm{ijdb} .130072 \mathrm{jd}$

\title{
Analysis of Cripto expression during mouse cardiac myocyte differentiation
}

\author{
JIU-ZHEN JIN, MIN TAN and JIXIANG DING* \\ Department of Molecular, Cellular \& Craniofacial Biology and Birth Defects Center, University of Louisville, \\ Louisville, KY, USA
}

\begin{abstract}
Vertebrate cardiac progenitor cells are initially allocated in two distinct domains, the first and second heart fields. It has been demonstrated that first heart field cells give rise to the myocardial cells in the left ventricle and part of the atria, whereas second heart field cells move into the developing heart tube and contribute to the myocardium of the outflow tract and right ventricle and the majority of atria. In this study, we have examined the expression of the mouse Cripto gene and the lineage of Cripto-expressing cells, focusing on its relationship with cardiac myocyte differentiation. The mouse Cripto gene is initially expressed at late head fold (LHF) stages in the cardiac crescent region, known as the first heart field; later in the medial region of the early heart tube, and by embryonic day 8.5, it is localized to the outflow tract. Using a Cripto-LacZ allele, we found that Cripto-expressing progeny cells contribute to the myocardium of the entire outflow tract and right ventricle, as well as to a majority of cells within the left ventricle. In contrast, no Cripto- expressing progeny cells were found in the atria or atrio-ventricular canal.Therefore, Cripto is transiently expressed in early differentiating myocardial cells of the left ventricle, right ventricle and outflow tract between LHF stages and E8.5. Cripto expression is subsequently downregulated as cells undergo further differentiation.
\end{abstract}

KEY WORDS: cripto, heart development, hear fields, myocyte differentiation

\section{Introduction}

The heart is the first functional organ formed during vertebrate embryogenesis. Heart formation involves a series of complex morphogenetic and differentiation events. Late in gastrulation, inductive signals from the anterior endoderm such as BMPs and Fgf8 specify cells in the anterior lateral mesoderm to become cardiac progenitor cells (Alsan and Schultheiss, 2002, Harvey, 2002, llagan et al., 2006, Schultheiss et al., 1997).

Cardiac precursor cells have been ascribed to two heart fields: the first and the second heart field (Laugwitz et al., 2008, Srivastava, 2006). Cells of the first heart field are the first to differentiate at cardiac crescent and early heart tube stages, and will give rise to the first heart lineage which largely contributes to the left ventricle and parts of the atria. The second heart field is located dorsal-medial to the first heart field at crescent stages and will give rise to second heart lineages which comprise the outflow tract, right ventricle, and a majority of cell within the atria
(Evans et al., 2010, Laugwitz et al., 2008, Srivastava, 2006, Watanabe and Buckingham, 2010). As development proceeds, cells within the cardiac crescent migrate toward the midline and fuse, forming an anterior-posterior oriented linear heart tube that subsequently undergoes rightward looping (Fishman and Chien, 1997, Harvey, 2002, Laugwitz et al., 2008, Olson and Srivastava, 1996, Srivastava, 2006, Srivastava and Olson, 2000). Following heart tube stages, the heart grows by addition of second heart field cells at both anterior and posterior poles of the heart (AbuIssa and Kirby, 2008, Cai et al., 2003, Kelly et al., 2001, Laugwitz et al., 2008, Srivastava, 2006). The contribution of pharyngeal mesoderm cells to the outflow tract was first demonstrated by dye labeling experiments in chick embryos (Waldo et al., 2001), and later in mouse embryos by genetic approaches using is/1Cre, isl-nlacZ, and Mlc1-lacZ mice (Cai et al., 2003, Kelly et

Abbreviations used in this paper: $\mathrm{LHF}$, late head fold; LV, left ventricle; RV, right ventricle.

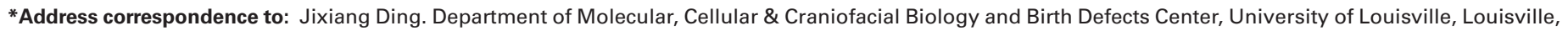
KY 40202, USA. Tel: +1-502-852-2455. Fax: +1-502-852-4702. E-mail: j0ding03@louisville.edu
} 
al., 2001, Sun et al., 2007). Is/1 mRNA is expressed only in the second heart field and pharyngeal mesoderm (Cai et al., 2003). Studies with $[\beta$-actin-LacZ;is/1-Cre] mouse embryos showed that over $90 \%$ of the cells in the outflow tract and the right ventricle are $\beta$-galactosidase positive demonstrating the contribution of second heart field cells to the outflow tract and right ventricle (Cai et al., 2003).

EGF-CFC proteins function as essential co-factors for several transforming growth factor- $\beta$ (TGF- $\beta$ ) superfamily members such as Nodal, GDFs and Vg-1, to signal through Activin receptors and control various aspects of vertebrate embryogenesis including the formation and patterning of the body plan (Chen et al., 2006, Cheng et al., 2003, Gritsman et al., 1999, Yeo and Whitman, 2001). The human CRIPTO gene, the founding member of EGF$C F C$ gene family, was first indentified in human teratocarcinoma cells (Ciccodicola et al., 1989). Subsequently, the mouse Cripto gene was cloned and shown to be expressed in embryonic mesoderm and developing heart (Dono et al., 1993, Johnson et al., 1994, Minchiotti et al., 2000). Studies with Cripto mutant mouse embryos demonstrated that Cripto plays critical roles in axial patterning, mesoderm and endoderm formation, and ventral midline formation (Chu et al., 2005, Ding et al., 1998, Xu et al., 1999). In addition, loss of Cripto function during ES cell differentiation blocks cardiac myocyte differentiation and promotes neural differentiation (Parisi et al., 2003, Xu et al., 1999). Further studies showed that Cripto acts through apelin/APJ to control cardiac lineage in ES differentiation (D'Aniello et al., 2009). These ES cell based studies strongly suggested that Cripto may play critical roles in heart development during embryogenesis in vivo. Previous studies on Cripto expression in heart development in vivo were performed mainly before the current two heart field model was formulated. To understand the precise role of Cripto in heart development, it is important to determine the Cripto expression during cardiogenesis in more detail. For example, Cripto was shown previously to express in the outflow tract on E8.5, and it is now known that outflow tract cells are derived from second heart field, and therefore, it is important to find out whether Cripto is expressed at early stage such as crescent stage, if so, it is in the first or second heart field. In addition, cells in the growing heart tube including the outflow tract region are very dynamical, it is critical to know where the Cripto-expressing progeny cells populate. In the present study, we attempted to address these questions, at least to some extent.

\section{Results and Discussion}

\section{Expression of Cripto during mouse cardiac development}

As shown in Fig. 1, Cripto mRNA expression was detected at the late head fold stage (LHF), specifically in a region possibly corresponding to the cardiac crescent (Fig. $1 \mathrm{~A}, \mathrm{E})$. At the 3-4 somite stage, expression was observed in a region consistent with the medial cardiomyocytes in the early heart tube (Fig. 1 B,F). Further examination using double in situ hybridization of Cripto with $\mathrm{MIC2a}$ demonstrated that these cells are Mlc2a positive, confirming they are indeed differentiating cardiomyocytes (see section 3 of the results and figure 3). At the 6-7 somite stage, Cripto is expressed in the dorsal region of the developing heart tube (Fig. $1 \mathrm{C}, \mathrm{G}$ ). On E8.5, when embryos contain 9-10 somites and have undergone cardiac looping, Cripto expression is restricted to outflow tract (Fig. $1 \mathrm{D}, \mathrm{H}$ ), consistent with previous studies showing a restricted Cripto expression in the outflow tract on E8.5 (Dono et al., 1993, Johnson et al., 1994, Minchiotti et al., 2000). At this stage, no Cripto mRNA is observed in pharyngeal mesoderm or foregut endoderm (Fig.1D). After E8.5, Cripto mRNA is no longer detectable by in situ hybridization.

\section{The progeny of Cripto expressing cells contribute to deriva- tives of the first heart field and anterior second heart field}

To locate the progeny of Cripto-expressing cells, we utilized a Cripto-Laczallele, in which the LacZgene is under the control of the endogenous Cripto promoter and recapitulates Cripto expression pattern (Ding et al., 1998). As $\beta$-galactosidase activity is stable, it has been widely used for lineage studies, including the fate of Cripto-expressing cells in axial mesendoderm (Chu et al., 2005, Ding et al., 1998). From the early somite stage to embryonic day 8.5 (E8.5), $\beta$ - galactosidase is present in a broader domain than that observed for Cripto mRNA (Fig. 2 A -D). Following heart looping, high levels of $\beta$-galactosidase activity are observed in the outflow tract and right and left ventricles, whereas CriptomRNA is restricted to outflow tract only as shown by previous studies (Dono et al., 1993, Johnson et al., 1994, Minchiotti et al., 2000) and the present study (Fig. $1 \mathrm{D}, \mathrm{H})$, indicating that the progeny of Cripto-expressing cells contribute to the ventricular region and to the outflow tract. On E9.5, when Cripto mRNA is no longer expressed in the heart, $\beta$ - galactosidase activity is retained in the outflow tract and right and left ventricles (Fig. $2 \mathrm{H}, \mathrm{I}$ ). However, no $\beta$-galactosidase positive cells are present in the atria or atrio-ventricular canal regions

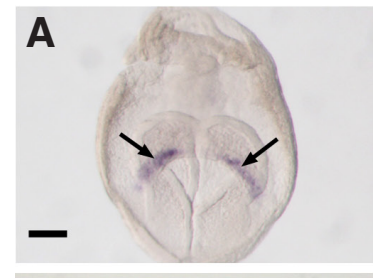

E
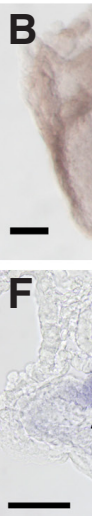

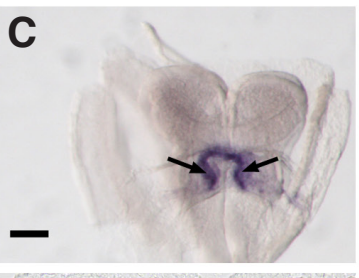

G
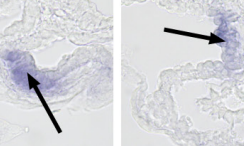

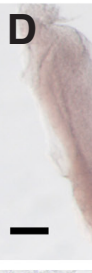

H

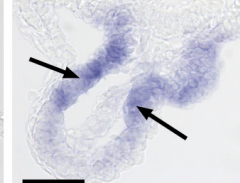

Fig. 1. Expression of Cripto mRNA during mouse heart formation. RNA in situ hybridization reveals Cripto expression (arrows) in mouse embryos at late head fold stage (LHF) (A,E), 3-4 somites stage (B,F), 6-7 somites stage $(\mathbf{C}, \mathbf{G})$ and 9-10 somites stage (D,H). Panels ( $E, F, G$ and $H)$

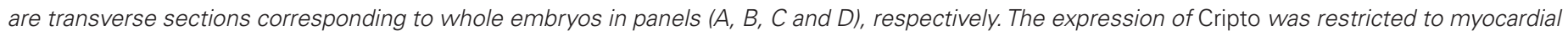
cells, and no expression was found in endocardial cells (G,H). Scale bars represent $200 \mu \mathrm{m} ;(A-D)$ and $50 \mu \mathrm{m}(E-H)$. 
(Fig. 2J). Serial sections revealed that $\beta$-galactosidase positive cells populate the majority of the myocardium in the outflow tract and in the right and left ventricle ventricles at E8.5 and E9.5 (Fig.2 $\mathrm{E}-\mathrm{G}$ and $\mathrm{K}-\mathrm{L})$. It is worth noting that the $\beta$-galactosidase staining in the left ventricle is weaker than the staining in the outflow tract and right ventricle (Fig. $2 \mathrm{D}, \mathrm{H}, \mathrm{I}$ ). Since the left ventricle is derived from the first heart field, the $\beta$-galactosidase in the left ventricle is inherited from the cardiac crescent cells on E7.5, whereas the $\beta$-galactosidase staining in the outflow tract and right ventricle represent the progeny of Cripto expressing cells from the early heart tube stage to E8.5.

\section{Cripto expressing cells and their progeny are always localized within Mlc2a expression domain}

To determine the Cripto expression domain in relation to first and second heart fields at the LHF/cardiac crescent stage, we performed double whole-mount in situ hybridization for Cripto and Mlc2a, an marker for early differentiating myocytes of the cardiac crescent (Cai et al., 2003, Laugwitz et al., 2008), and found that Cripto-expressing cells (purple) are exclusively localized within the Mlc2a expression domain (red) in the cardiac crescent (Fig. 3 A-F). Fig. 3A is a mouse embryo at the LHF stage showing Cripto expression only, and the same embryo was subjected to detection for Mlc2a expression, as shown in Fig. 3B. Cripto-expressing and Mlc2a- expressing cells were co-localized in the crescent region as revealed by section analysis (Fig. $3 \mathrm{C}$ ). It is important to note that not all the cells in the crescent were Cripto positive. Instead, only the region immediately adjacent to the second heart field were positive for both Cripto and MIc2a, whereas crescent cells distal to the second heart field were positive only for Mlc2a expression. At early somite stages when the linear heart tube starts to form, Cripto positive cells were restricted to the medial domain of $\mathrm{Mlc2a}$ expression (Fig. 3 D-F).
We next investigated the location of the progeny of Cripto expressing cells in relation to differentiated myocytes within the early looping heart using $\beta$ - galactosidase staining in combination with Mlc2a in situ hybridization in Cripto ${ }^{\mathrm{Lacz} / \mathrm{Wt}}$ embryos at early heart looping stages. Fig. $3 G$ shows a $\beta$-galactosidase stained Cripto $^{L a c z / W t}$ embryo. The same embryo was subjected to Mlc2a in situ hybridization and the strong MIc2a signal masks the previous $\beta$-galactosidase signal (Fig. $3 \mathrm{H}$ ). In sections, $\beta$-galactosidase signal is also completely masked by signal from Mlc2a mRNA in situ (Fig. 3I), with the exception of scattered $\beta$-galactosidase signals in the endoderm, which are likely to be remnants of early Cripto expression in axial mesoendoderm (Chu et al., 2005). Therefore, Cripto-expressing cardiac progenitor cells and their progeny are restricted to differentiating myocyte cells of the first and anterior second heart fields.

We next sought to examine the relationship between Criptoexpressing cells and the second heart field by double in situ hybridization for Cripto (in red) and Is/1 (dark purple) at crescent stages, and found that Is/1 mRNA was located dorsal-medial to the Cripto expression domain with no overlap (Fig. 3J). We also investigated the location of the progeny of Cripto expressing cells in relation to the second heart field by $\beta$-galactosidase staining in combination with Is/1 in situ hybridization in Cripto ${ }^{\text {Lacz } / W t}$ embryos at later stages, and found that at linear heart tube stages, Is/1 mRNA was expressed in endoderm and pharyngeal mesenchymal cells distinct from $\beta$-gal positive cells (Fig. $3 \mathrm{~K}, \mathrm{~L}$ ).

The foregoing observations are consistent with Cripto being expressed in distinct subpopulations of cardiomyocytes as they first differentiate.

The Cripto expression domain is immediately adjacent to the second heart field. It has been reported previously that this region is positive for Isl1 protein expression, although it is negative for Is/1 mRNA expression (Prall et al., 2007, Sun et al., 2007). To test
Fig. 2. $\beta$-galactosidase staining pattern in Cripto Cacz/Wt $^{\text {Lat }}$ embryos. At the 3-4 somite stage (A), 6-7 somite stage (B), 11-12 somite stage (C-G) and E9.5 (H-L). (D,I) frontal views; $\mathbf{( C , H ) ~ r i g h t ~ s i d e ~ v i e w , ~ w h e r e a s ~}$ (J) is left side view. (E, F,K) Cross sections, whereas $(\mathbf{G}, \mathbf{L})$ sagittal sections. At early somite stages, $\beta$-galactosidase staining positive cells were found in the entire myocardium (arrows in A and B). On E8.25-8.5 with 11-12 somites, intense staining was found in the outflow tract and right ventricle (arrows in C and D) with slightly weak signals in the left ventricle (shot arrow in D). E9.5 embryos showed a similar pattern in the outflow tract, right ventricle and left ventricle regions (arrows in $H$ and I). However, no signal was found in the atria or atrioventricular canal (arrow in J). The
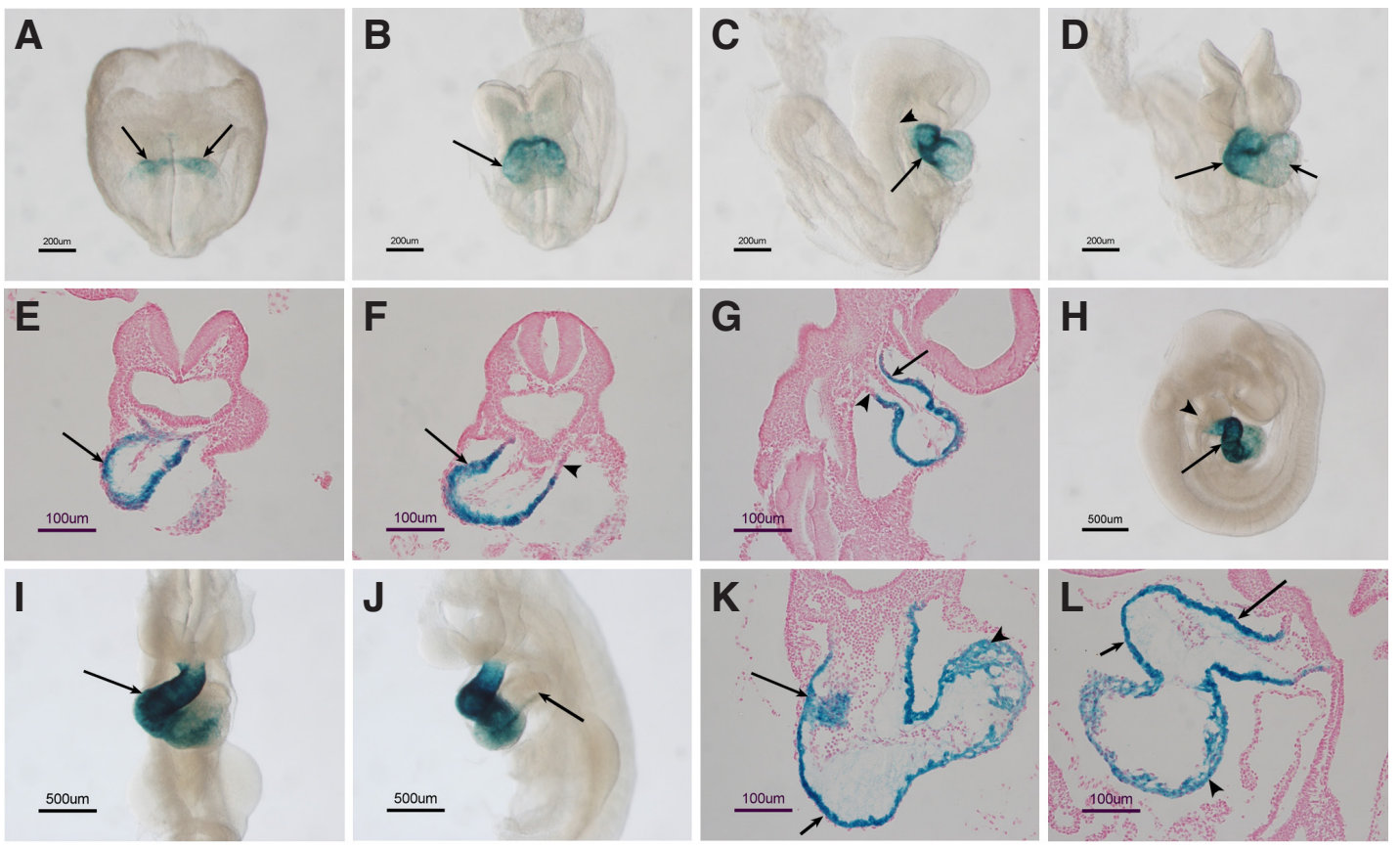

majority of myocardial cells in the outflow tract (arrows in $E, F, G, K$ and L), right ventricle (short arrows in $K$ and L) and left ventricle (arrowheads in $K$ and $L$ ) were blue and only a few unstained cells were found (arrowheads in $F, G$, ). No signal was found in the pharyngeal mesoderm (arrowheads in $C$ and H). Scale bars represent $200 \mu \mathrm{m}(\mathrm{A}-\mathrm{D}), 100 \mu \mathrm{m}$ (E-G and K-L), $500 \mu \mathrm{m}(\mathrm{H}-\mathrm{J})$. 

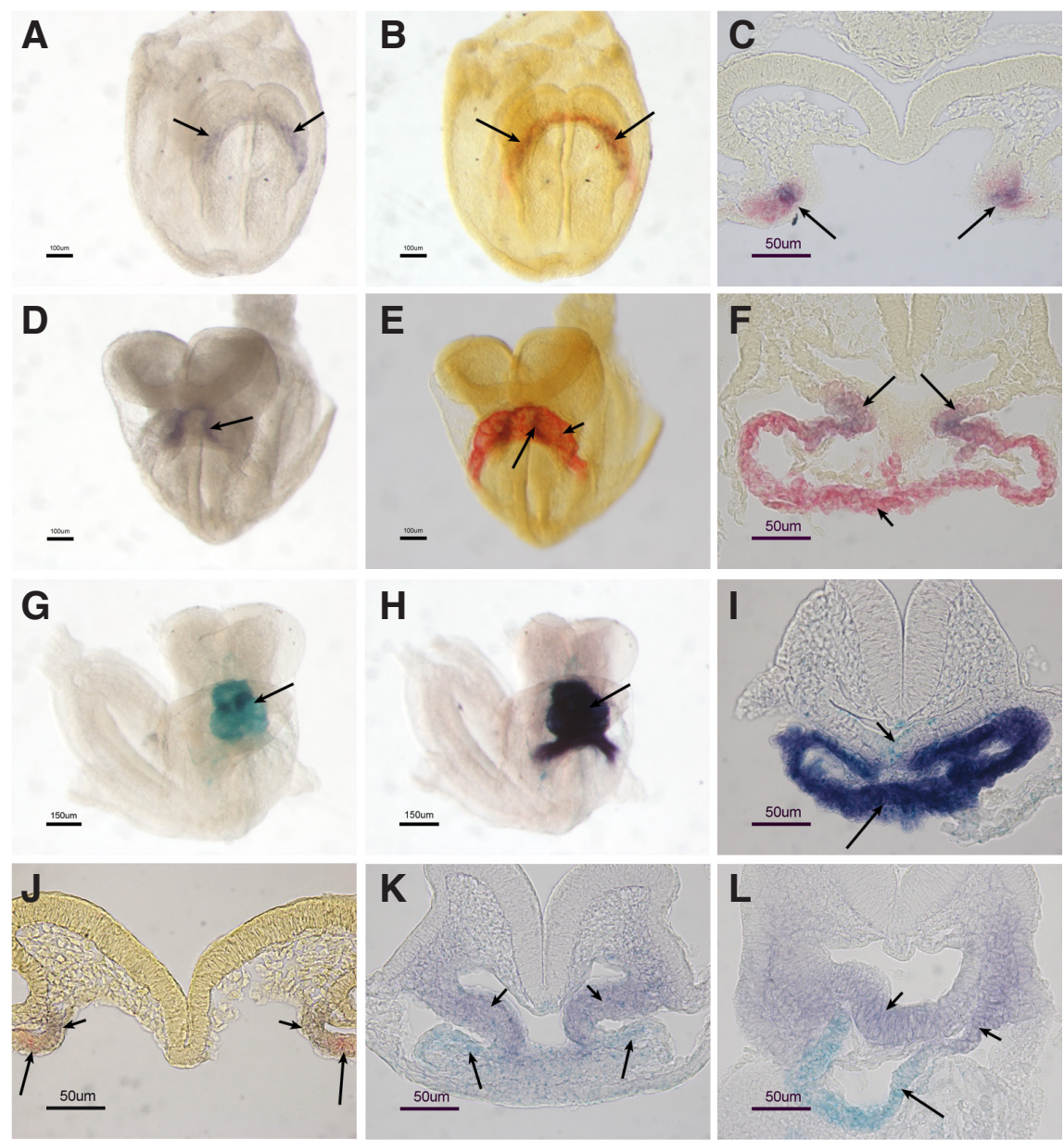

Fig. 3. Cripto-expressing cells and their progeny are located within the MIc2a expression domain and are distinct from the domain of Is/1 expression area. (A-F) Double in situ hybridization of Cripto (purple) and Mlc2a (red) in wild type embryos showing Cripto-expressing cells are localized within the Mlc2a expression region in the cardiac crescent (arrows in A-C). Once the heart tube is formed, they are co-localized in the anterior heart tube (arrows in D-F), whereas the rest heart tube was positive only for Mlc2a (short arrows in $E$ and F). (G-I) $\beta$-galactosidase staining (G) followed by Mlc2a in situ hybridization ( $H$ and I) in Cripto ${ }^{\text {LacZNAt }}$ embryos at the early heart looping stage showing that the Mlc2a in situ hybridization signal completely overlays the $\beta$-galactosidase staining (arrows in G-I), only a few scattered $\beta$-galactosidase positive cells were observed in the foregut endoderm (short arrow in I). (J) Double in situ hybridization showing Isl1 expression in purple (short arrows) and Cripto expression domain in red (arrows) in the cardiac crescent of wild type embryos. $(\mathbf{K}, \mathbf{L}) \beta$-galactosidase staining followed by Isl1 in situ hybridization showing Cripto-lineage cells in blue larrows) are distinct from the Isl1-expressing pharyngeal mesenchymal cells (short arrows). whether Cripto expressing cells are Isl1 protein positive, we carried out Isl1 immunostaining and Cripto in situ hybridization in adjacent sections and found that Cripto mRNA expression domain is more broad than Isl1 protein expression domain in the heart tube, and the two domains partially overlap in the dorsal portion of the heart tube (see Supplementary Figure).

In conclusion, the Cripto gene has two phases of expression during mouse cardiac development from the LHF stage to E8.5. At the LHF stage, Cripto is highly expressed in differentiating myocytes in the cardiac crescent that will give rise to the cells of the future left ventricle, but not the atria. From early heart tube stages, cells in the second heart field migrate into the developing heart tube through anterior and posterior poles of the tube and differentiate into myocytes. Previous studies have demonstrated that second heart field cells that migrate through anterior pole will contribute to the myocardial cells in the outflow tract and right ventricle, whereas the cells that move via the posterior pole will contribute to the majority of the atria (Cai et al., 2003, Evans et al., 2010, Waldo et al., 2001). During this process, expression of Cripto mRNA is initially restricted to the medial region of early heart tube, and later (E8.5) to the outflow tract of the heart tube. In contrast, the progeny of Cripto expressing cells populate the right and left ventricles as well as the outflow tract at E8.5 and E9.5. Since Cripto mRNA is not expressed in the right ventricle, it appears that Cripto expression specifically marks differentiating myocytes of the anterior developing heart tube, namely, when second heart field cells are migrating through the anterior pole of the developing heart tube and differentiating to myocytes, these cells express Cripto, but only transiently, as the expression soon disappears once the cells undergo further differentiation. Since Cripto-expressing cells and their progeny cells are not detected in the atrial region, second heart field cells that migrate through the posterior pole of the developing heart tube do not express Cripto as they are differentiating into myocytes.

\section{Materials and Methods}

\section{Mouse strains and mutant alleles}

The Cripto ${ }^{\mathrm{acz}}$ allele has been reported previously (Ding et al., 1998). In this allele, the expression of Lacz gene is controlled by the endogenous Cripto promoter, which recapitulates Cripto expression in vivo. In addition, we performed in situ hybridization using a LacZ gene probe on Cripto ${ }^{\text {lacz }}$ wt embryos and found the expression of LacZ mRNA was identical to the expression of Cripto mRNA (data not shown).

Embryos between E7.5-E8.0 were staged according to Downs and Davis (Downs and Davies, 1993) and by somite number. Embryos from E8.5 to E9.5 were staged by gestation days, the day a plug observed was designated as day 0.5 (E0.5). For any given stage, at least 10 embryos are used for each experiment.

\section{In situ hybridization and $\beta$-galactosidase staining}

Single probe whole-mount in situ hybridization was carried out as previously described (Shen, 2001). A plasmid containing full length Cripto cDNA 
was used to generate the probe for Cripto in situ (Ding et al., 1998). Probes for MIc2a and Is/1 were provided by Dr. Sylvia Evans at UCSD (Cai et al., 2003). Double color whole-mount in situ hybridization protocol was based on(Cai et al., 2003). Briefly, Digoxigenin and Fluorescein labeled antisense RNA probes were hybridized simultaneously, followed by first blue color reaction using anti-Digoxigenin-AP Fab fragments and NBT/BCIP as the conventional single color in situ hybridization. The second red color detection was visualized by anti-Fluorescein-POD Fab fragments (Roche) and Fast Red. Following the first color development, the embryos were incubated at high temperature followed by treatment with $4 \%$ paraformaldehyde and glycine in order to completely inactivate alkaline phosphatase activity. For comparison and documentation, we usually photographed embryos individually before the second color reaction.

Whole-mount $\beta$-galactosidase staining was performed using standard procedure. Briefly, E7.5-9.5 embryos were fixed in 4\% paraformaldehyde at $4^{\circ} \mathrm{C}$ for $50-60$ minutes and incubated with staining solution (phosphate buffered saline, $\mathrm{pH} 7.4,2 \mathrm{mM} \mathrm{MgCl}, 0.02 \%$ Nonidet $\mathrm{P}-40(\mathrm{v} / \mathrm{v}), 5 \mathrm{mM}$ potassium ferricyanide, $5 \mathrm{mM}$ potassium ferrocyanide, and $1 \mathrm{mg} / \mathrm{ml} \mathrm{X-gal)}$ for $4-6$ hours at $37^{\circ} \mathrm{C}$. Stained embryos were post-fixed with $10 \%$ formalin for at least 24 hours. To combine in situ hybridization with $\beta$-galactosidase staining, embryos were first stained for $\beta$-galactosidase under RNase free conditions and then fixed overnight in $4 \%$ paraformaldehyde at $4{ }^{\circ} \mathrm{C}$ followed by washes with PBT (PBS with $0.1 \%$ Tween-20) and stored at $-20^{\circ} \mathrm{C}$ in methanol until processed for in situ hybridization.

\section{Acknowledgements}

We thank Dr. Sylvia Evans at University of California, San Diego for her advices during this study. Our thanks also go to Dr. Dennis Warner and Dr. Lisa Sandell for their comments on the manuscript and Hong Li for her technical assistance. Research reported in this publication was supported by an Institutional Development Award (IDeA) from the National Institute of General Medical Sciences of the National Institutes of Health under grant number P20GM103453, and research grants from National Institutes of Health (DE015565 and DE016845) and Kentucky Science \& Engineering Foundation (KSEF-148-502-10-258) to J.D.

\section{References}

ABU-ISSA, R. and KIRBY, M.L. (2008). Patterning of the heart field in the chick. Dev Biol 319: 223-233.

ALSAN, B.H. and SCHULTHEISS, T.M. (2002). Regulation of avian cardiogenesis by Fgf8 signaling. Development 129: 1935-1943.

CAI, C.L., LIANG, X., SHI, Y., CHU, P.H., PFAFF, S.L., CHEN, J. and EVANS, S. (2003). Isl1 identifies a cardiac progenitor population that proliferates prior to differentiation and contributes a majority of cells to the heart. Dev Cell 5: 877-889.

CHEN, C., WARE, S.M., SATO, A., HOUSTON-HAWKINS, D.E., HABAS, R., MATZUK, M.M., SHEN, M.M. and BROWN, C.W. (2006). The Vg1-related protein Gdf3 acts in a Nodal signaling pathway in the pre-gastrulation mouse embryo. Development 133: 319-329.

CHENG, S.K., OLALE, F., BENNETT, J.T., BRIVANLOU, A.H. and SCHIER, A.F. (2003). EGF-CFC proteins are essential coreceptors for the TGF-beta signals Vg1 and GDF1. Genes Dev 17: 31-36.

CHU, J., DING, J., JEAYS-WARD, K., PRICE, S.M., PLACZEK, M. and SHEN, M.M. (2005). Non-cell-autonomous role for Cripto in axial midline formation during vertebrate embryogenesis. Development 132: 5539-5551.

CICCODICOLA, A., DONO, R., OBICI, S., SIMEONE, A., ZOLLO, M. and PERSICO, M.G. (1989). Molecular characterization of a gene of the 'EGF family' expressed in undifferentiated human NTERA2 teratocarcinoma cells. EMBO J8: 1987-1991.

D'ANIELLO, C., LONARDO, E., IACONIS, S., GUARDIOLA, O., LIGUORO, A.M., LIGUORI, G.L., AUTIERO, M., CARMELIET, P. and MINCHIOTTI, G. (2009). G protein-coupled receptor APJ and its ligand apelin act downstream of Cripto to specify embryonic stem cells toward the cardiac lineage through extracellular signal-regulated kinase/p70S6 kinase signaling pathway. Circ Res 105: 231-238.
DING, J., YANG, L., YAN, Y.T., CHEN, A., DESAI, N., WYNSHAW-BORIS, A. and SHEN, M.M. (1998). Cripto is required for correct orientation of the anteriorposterior axis in the mouse embryo. Nature 395: 702-707.

DONO, R., SCALERA, L., PACIFICO, F., ACAMPORA, D., PERSICO, M.G. and SIMEONE, A. (1993). The murine cripto gene: expression during mesoderm induction and early heart morphogenesis. Development 118: 1157-1168.

DOWNS, K.M. and DAVIES, T. (1993). Staging of gastrulating mouse embryos by morphological landmarks in the dissecting microscope. Development 118: 1255-1266.

EVANS, S.M., YELON, D., CONLON, F.L. and KIRBY, M.L. (2010). Myocardial lineage development. Circ Res 107: 1428-1444.

FISHMAN, M.C. and CHIEN, K.R. (1997). Fashioning the vertebrate heart: earliest embryonic decisions. Development 124: 2099-2117.

GRITSMAN, K., ZHANG, J., CHENG, S., HECKSCHER, E., TALBOT, W.S. and SCHIER, A.F. (1999). The EGF-CFC protein one-eyed pinhead is essential for nodal signaling. Cell 97: 121-132.

HARVEY, R.P. (2002). Patterning the vertebrate heart. Nat Rev Genet 3: 544-56.

ILAGAN, R., ABU-ISSA, R., BROWN, D., YANG, Y.P., JIAO, K., SCHWARTZ, R.J., KLINGENSMITH, J. and MEYERS, E.N. (2006). Fgf8 is required for anterior heart field development. Development 133: 2435-2445.

JOHNSON, S.E., ROTHSTEIN, J.L. and KNOWLES, B.B. (1994). Expression of epidermal growth factor family gene members in early mouse development. Dev Dyn 201: 216-226.

KELLY, R.G., BROWN, N.A. and BUCKINGHAM, M.E. (2001). The arterial pole of the mouse heart forms from Fgf10-expressing cells in pharyngeal mesoderm. Dev Cell 1: 435-440.

LAUGWITZ, K.L., MORETTI, A., CARON, L., NAKANO, A. and CHIEN, K.R. (2008). Islet1 cardiovascular progenitors: a single source for heart lineages? Development 135: 193-205.

MINCHIOTTI, G., PARISI, S., LIGUORI, G., SIGNORE, M., LANIA, G., ADAMSON, E.D., LAGO, C.T. and PERSICO, M.G. (2000). Membrane-anchorage of Cripto protein by glycosylphosphatidylinositol and its distribution during early mouse development. Mech Dev 90: 133-142.

OLSON, E.N. and SRIVASTAVA, D. (1996). Molecular pathways controlling heart development. Science 272: 671-676.

PARISI, S., D'ANDREA, D., LAGO, C.T., ADAMSON, E.D., PERSICO, M.G. and MINCHIOTTI, G. (2003). Nodal-dependent Cripto signaling promotes cardiomyogenesis and redirects the neural fate of embryonic stem cells. J Cell Biol 163: 303-314.

PRALL, O.W., MENON, M.K., SOLLOWAY, M.J., WATANABE, Y., ZAFFRAN, S., BAJOLLE, F., BIBEN, C., MCBRIDE, J.J., ROBERTSON, B.R., CHAULET, H. et al., (2007). An Nkx2-5/Bmp2/Smad1 negative feedback loop controls heart progenitor specification and proliferation. Cell 128: 947-959.

SCHULTHEISS, T.M., BURCH, J.B. and LASSAR, A.B. (1997). A role for bone morphogenetic proteins in the induction of cardiac myogenesis. Genes Dev 11: 451-462.

SHEN, M.M. (2001). Identification of differentially expressed genes in mouse development using differential display and in situ hybridization. Methods 24: 15-27.

SRIVASTAVA, D. (2006). Making or breaking the heart: from lineage determination to morphogenesis. Cell 126: 1037-1048.

SRIVASTAVA, D. and OLSON, E.N. (2000). A genetic blueprint for cardiac development. Nature 407: 221-226.

SUN, Y., LIANG, X., NAJAFI, N., CASS, M., LIN, L., CAI, C.L., CHEN, J. and EVANS, S.M. (2007). Islet 1 is expressed in distinct cardiovascular lineages, including pacemaker and coronary vascular cells. Dev Biol 304: 286-296.

WALDO, K.L., KUMISKI, D.H., WALLIS, K.T., STADT, H.A., HUTSON, M.R., PLATT, D.H. and KIRBY, M.L. (2001). Conotruncal myocardium arises from a secondary heart field. Development 128: 3179-3188.

WATANABE, Y. and BUCKINGHAM, M. (2010). The formation of the embryonic mouse heart: heart fields and myocardial cell lineages. Ann N Y Acad Sci 1188: 15-24.

XU, C., LIGUORI, G., PERSICO, M.G. and ADAMSON, E.D. (1999). Abrogation of the Cripto gene in mouse leads to failure of postgastrulation morphogenesis and lack of differentiation of cardiomyocytes. Development 126: 483-494.

YEO, C. and WHITMAN, M. (2001). Nodal signals to Smads through Cripto-dependent and Cripto-independent mechanisms. Mol Cell 7: 949-957. 


\section{Further Related Reading, published previously in the Int. J. Dev. Biol.}

Nodal/Cripto signaling in fetal male germ cell development: implications for testicular germ cell tumors Cassy M. Spiller, Josephine Bowles and Peter Koopman

Int. J. Dev. Biol. (2013) 57: 211-219

Global irradiation effects, stem cell genes and rare transcripts in the planarian transcriptome Mireille Galloni

Int. J. Dev. Biol. (2012) 56: 103-116

Characterization of the functional properties of the neuroectoderm in mouse Cripto -/- embryos showing severe gastrulation defects

Giovanna L. Liguori, Diego Echevarria, Sonia Bonilla, Daniela D’Andrea, Annamaria Liguoro, Maria G. Persico, and Salvador Martinez

Int. J. Dev. Biol. (2009) 53: 549-557

Creating frog heart as an organ: in vitro-induced heart functions as a circulatory organ in vivo

Masayoshi Kinoshita, Takashi Ariizumi, Shinsuke Yuasa, Shunichirou Miyoshi, Shinji Komazaki, Keiichi Fukuda and Makoto Asashima

Int. J. Dev. Biol. (2010) 54: 851-856

Int. J. Dev. Biol. (2010) 54: 851-856 A novel mutant allele of Ncx1: a single amino acid substitution leads to cardiac dysfunction

Carolien Wansleeben, Harma Feitsma, Leon Tertoolen, Carla Kroon, Victor Guryev, Edwin Cuppen and Frits Meijlink

Int. J. Dev. Biol. (2010) 54: 1465-1471

5 yr ISI Impact Factor $(2011)=2.959$

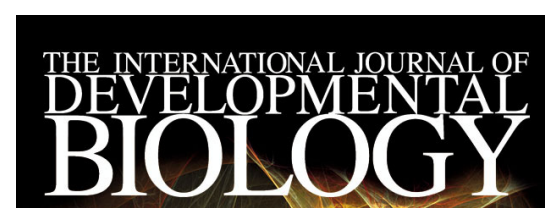

Volume 50 Nos. 2/3 VIstedial Issue

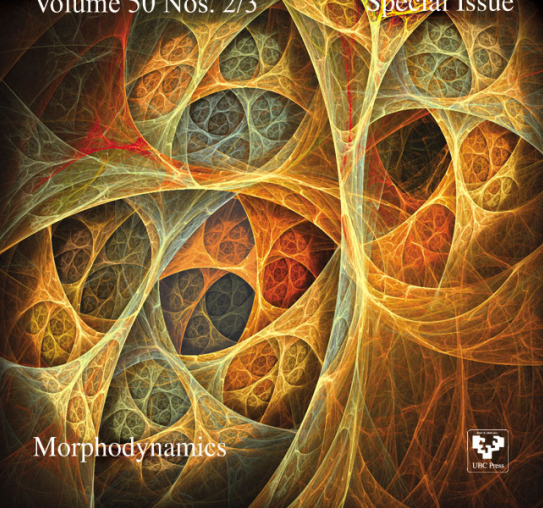

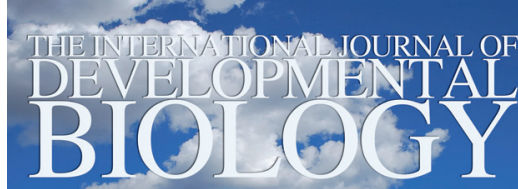

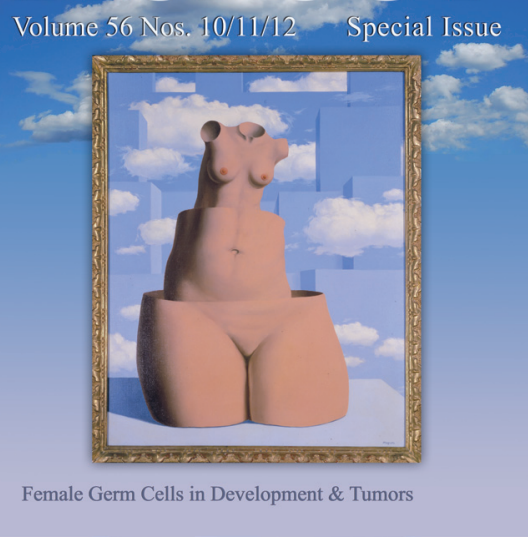

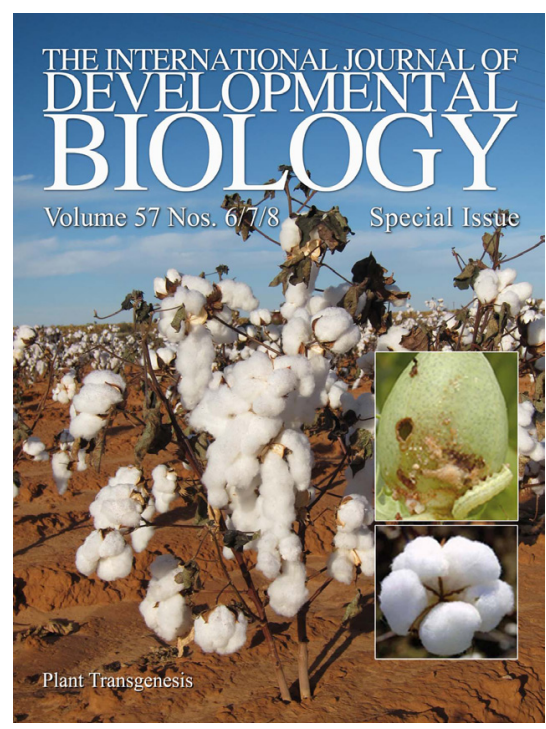

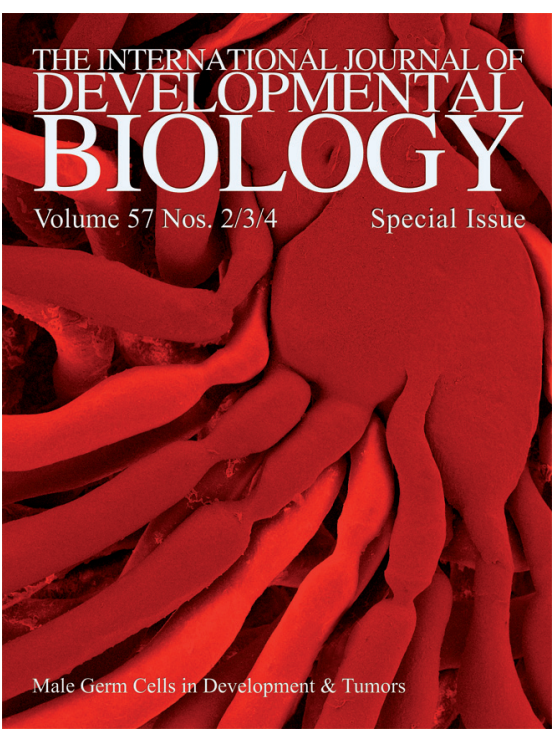

